\title{
Territorial Behavior of a Green Hairstreak Chrysozephyrus smaragdinus (Lepidoptera: Lycaenidae): Site Tenacity and Wars of Attrition
}

\author{
Tsuyoshi Takeuchi* and Michio Imafuku \\ Department of Zoology, Graduate School of Science, Kyoto University, \\ Sakyo, Kyoto 606-8502, Japan
}

\begin{abstract}
Males of Chrysozephyrus smaragdinus were active from late morning to late afternoon, during which they showed territorial behavior, perhaps for mating. The territorial male stayed in a particular area and occasionally flew around it, referred to hereafter as the inspection area. When other male intruded into this area, the territorial male rushed to him. Then, they engaged in a circling flight regarded as a "war of attrition". During this flight, the two males sometimes strayed far away from the territory. After the circling flight, the resident returned to his territory in almost all cases (98\%). Despite such intrusions, many residents defended their territory for several successive days. This suggests strongly the "effect of prior residence". We recorded the circling flights with a high-speed video camera, and confirmed that the male that ceased the circling flight first was the loser. This finding gave some validity to consider circling flight as wars of attrition. In a few cases, the territorial male mated with a female that came to the territory. These once mated males held the territory no longer, suggesting that mating experience should restrict the next mating opportunity in this species.
\end{abstract}

Key words: butterfly, territoriality, residency, wars of attrition

\section{INTRODUCTION}

The definition of an animal's territory was vague until Noble (1939) defined it as "any defended area". Wilson (1975) defined territory more precisely as "an area occupied more or less exclusively by animals or group of animals by means of repulsion through overt aggression or advertisement". A territory is hence an exclusive area against other individuals for resources including food, mates, or breeding. Territorial behavior has been reported for many vertebrates (Hasegawa and Tanemura, 1986) and invertebrates including a variety of insects, such as wasps (e.g. Alcock and Bailey, 1997), damselflies (e.g. Waage, 1988), and butterflies (reviewed by Kemp and Wiklund, 2001).

In many butterfly species, the male defends from conspecific males a specific area which seems to have no valuable resources such as food or oviposition site (e.g. Davies, 1978; Lederhouse, 1982). This behavior was thought to increase the territory-holder's mating opportunity: frequent mating has been observed in these male territories in some butterfly species (e.g. Cordero and Soberón, 1990; Fischer

\footnotetext{
* Corresponding author. Phone: +81-75-753-4099; Fax : +81-75-753-4075; E-mail: takeuchi@ethol.zool.kyoto-u.ac.jp
}

and Fiedler, 2001). Butterfly males compete for ownership of a territory through conspicuous aerial interactions in which two males encircle each other until one of them gives up (Kemp and Wiklund, 2001). This behavior is called circling flight. Such a butterfly fights have been regarded as "wars of attrition", where both contestants continuously display and the one that retreats earlier is the loser (Maynard Smith, 1982). In general, butterflies appear to lack any obvious morphological traits to attack their opponents and rarely attack the opponent physically during the fight. The means by which butterflies settle a dispute over a territory remains a mystery. Investigating these territorial butterfly fights therefore provides insight into the nature of weaponless duels and the diversity of animal fights.

Chrysozephyrus smaragdinus (Lycaenidae) is a small butterfly (wing span 18-23 mm) and is sexually dimorphic; males exhibit brilliant green dorsal surface of the wings due to interference of light, whereas females are dark brown with an orange spot (Imafuku et al., 2002). The larval food plant is some species of cherry, genus Prunus. The butterfly is arboreal, inhabiting temperate deciduous forests and univoltine. In Japan, adults appear in June and July, the Japanese rainy season. The adult season at a given site is rather short, lasting for approximately a month. Males of this species persist to a small open space in forest and compete 
with other males for the area via circling flight. Although $C$. smaragdinus lives in an arboreal habitat and is not easy to observe or catch, it is an ideal subject for investigating territorial behavior of butterflies as males of this species appears to show circling flight more frequently and for longer periods than other butterfly species in Japan (Fukuda et al., 1984). In this study, we investigated the characteristics of territorial behavior of $C$. smaragdinus. We observed and recorded the daily pattern of male appearance at the territory, territory range, which individual occupied the territory, and male-male contest behavior.

\section{MATERIALS AND METHODS}

Our studies were made mainly in Shiojiri City $\left(36^{\circ} 00^{\prime} \mathrm{N}\right.$, $137^{\circ} 50^{\prime} \mathrm{E}, 1000 \mathrm{~m}$ alt), Nagano Prefecture, Japan, from 12 to 21 July 2001, 3 to 16 July 2002, and 4 to 31 July 2003. The study site was a south facing valley in a temperate deciduous forest, with tall trees over $20 \mathrm{~m}$ in height. At this site, the butterfly was found on trees along a stream. In 2001, we observed butterflies in quite a restricted area (approximately $10 \mathrm{~m} \times 10 \mathrm{~m}$ ) where we could look down on butterflies on trees from a bridge, and in 2002 and 2003, along an approximately $300 \mathrm{~m}$ transect along a stream. As the adult season at a given site was short and observation at one site was restricted, we made additional observations in Nagano City (36³9'N, 138 $10^{\circ} \mathrm{E}, 400 \mathrm{~m}$ alt), Nagano Prefecture, in June 1999 , June 2002, June 2003, and June 2004, where the butterfly emerges approximately three weeks earlier than in Shiojiri City. This study site is also a temperate deciduous forest, with tall trees over $20 \mathrm{~m}$ in height. The butterfly was found around an artificial gap in the forest, formerly used for farming. For the investigation of territorial behavior, males at both study sites were captured at the first sight and marked with water-insoluble ink along the edges of the ventral surface of both left and right wings. Presented data were collected in Shiojiri City unless otherwise mentioned.

To obtain data on the daily activity pattern, we surveyed the

(a)

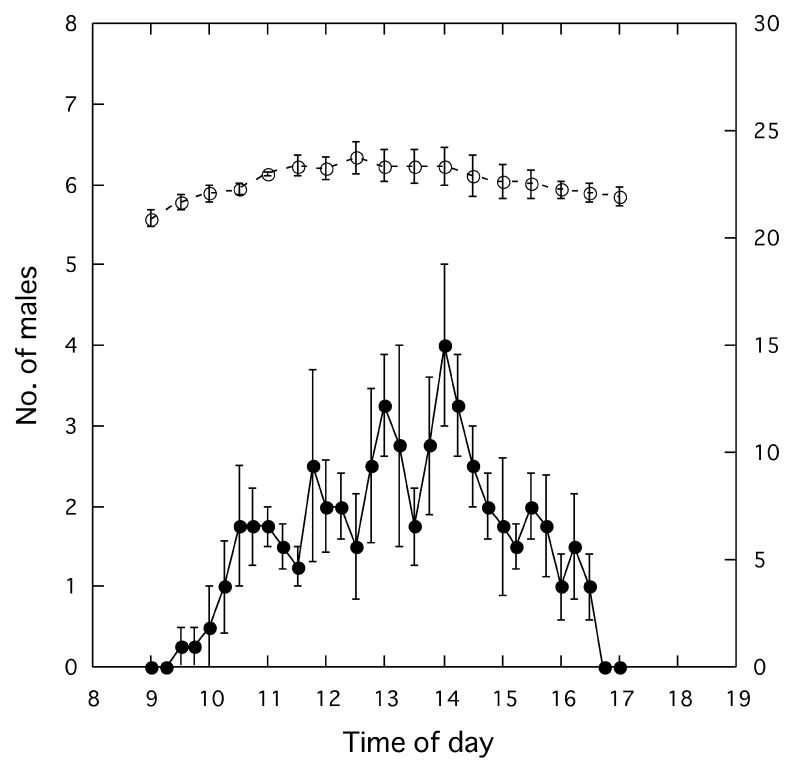

study sites for flying or perching butterflies every 5 min from 9:00 to $18: 00$ for 4 days each in Nagano City in June 1999 and in Shiojiri City in July 2001. Air temperature was measured with a thermometer hung on a tree at $1.5 \mathrm{~m}$ height in the shade.

To determine the number of successive days a male occupied the same territory (the territory tenure time), we recorded which males occupied each territory every day. Males that perched in a territory when the territorial male was taken out for marking were not counted. Because our study period did not cover the whole adult season, the territory tenure time should be underestimated in some cases.

Territorial males occasionally made spontaneous flights in a limited range around the perching point, which is referred to as the 'inspection area' hereafter. We defined the territory area as the range of the inspection area (Takeuchi and Imafuku, 2005). When another male intruded into a territory, the territorial male rushed over to him. Then interaction (circling flight and/or chase) between them occurred. After the interaction one of them returned to the territory. This individual was defined as the winner of the contest. We observed circling flights and recorded the winner of each fight, and when possible, we recorded circling flight with a high-speed video camera at a rate of 250 frames $/ \mathrm{sec}\left(c^{3}\right.$ camera; Nac Image Technology) to determine whether the male that first ceased the circling flight is really the loser. This is the premise of "wars of attrition" (Maynard Smith, 1982), but to our knowledge it has not been confirmed accurately in butterfly fights.

The inspection area of a single territorial male was plotted on a map in Nagano City on 26 June 1999. The initiation and termination points of the circling flight were also plotted on the map.

\section{RESULTS}

\section{Daily activity}

Males flew to study sites in the morning and flew away from study sites in the evening. The 4-day observation in Nagano City in June 1999 revealed that males were active between 10:00 and 17:00 (Fig. 1a). The average air temper-

(b)

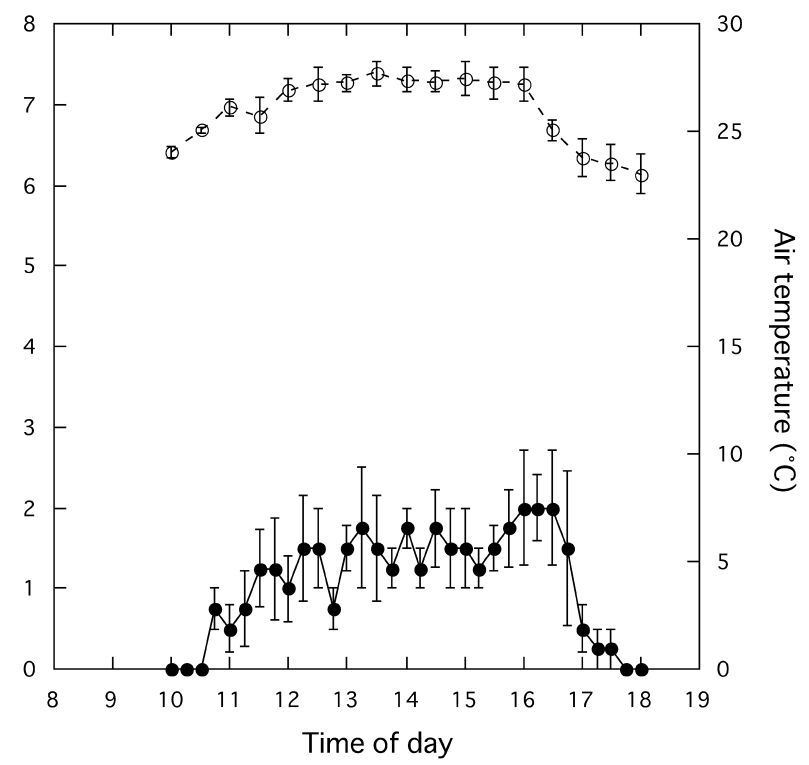

Fig. 1. Daily activity of Chrsozephyrus smaragdinus in Nagano City in June 1999 (a) and in Shiojiri City in July 2001 (b). The mean number of male $C$. smaragdinus observed in the study area (solid circles) and mean air temperature (open circles, ${ }^{\circ} \mathrm{C}$ ) are shown. The error bars represent standard errors of each mean. 
ature during the observation period was $22.6^{\circ} \mathrm{C}$, and it was mostly cloudy. During the 4-day observation in Shiojiri City in July 2001, males were active between 11:00 and 18:00 (Fig. 1b). The average air temperature during the observation period was $26.0^{\circ} \mathrm{C}$, and it was mostly sunny.

During the active time, a male typically perched on some fixed points in a restricted area, such as a tip of a shoot or a twig of a tree. He occasionally made spontaneous flights in a limited range (ca. 15-25 $\mathrm{m}^{2}$ ), around the perch points without being approached by other individuals. When other insects intruded into a territory, he immediately chased it away. When other male intruded into a territory, he rushed to the male. In some cases, the intruder immediately flew away when chased by the territorial male. In other cases, the two males engaged in a circling flight. When the circling flight was ceased, a chase ensued along a horizontal plane, and soon one of the males returned to the territory.

\section{Territory}

The territory tenure time ranged from 1 to 28 days (Fig. $2 a)$. Fig. $2 b$ shows the number of males that continued to occupy the same territory at least for the number of days shown on the abscissa (like survivorship curve). Once a male had occupied a territory for two days, he was highly likely to be found in that territory on the following days (Fig. $2 b)$. These males were different from males occupying the territories for only 1 day in that the former flew away from their territories at the end of daily activity, and returned to the same places the next morning. The mean territory tenure time of these males was 9.0 days \pm 1.4 days (SE). They were defined as a resident. Residents that disappeared from the territory for one or more days never reappeared at that

(a)

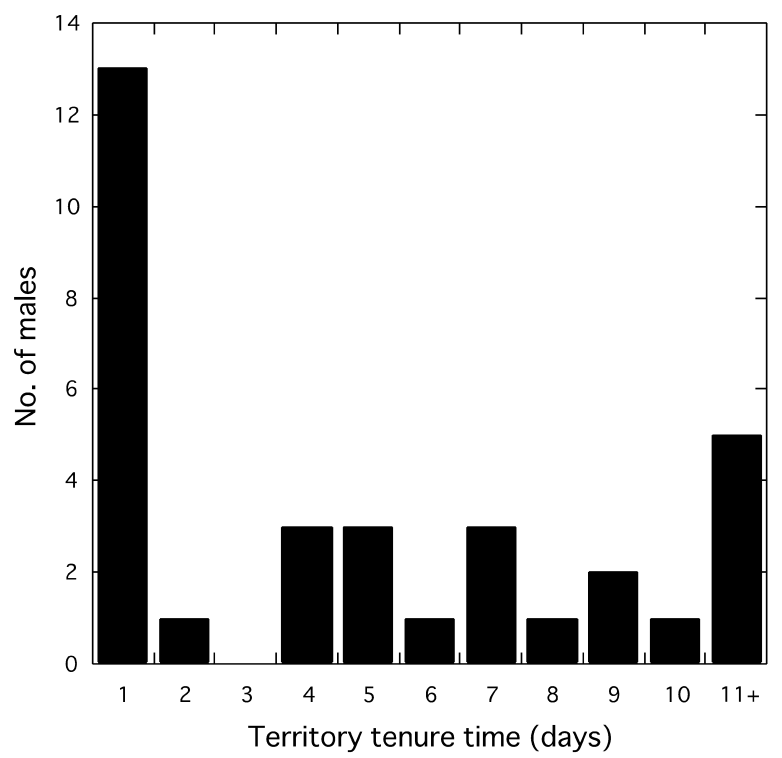

territory. The same places were used as territories by different males at different period in an adult season. They are also used repeatedly in different years. A common feature of territories seems to be a small open space (ca. $15-25 \mathrm{~m}^{2}$ ) in a forest surrounded by a "wall of trees". We found no larval food plants in the territories. There were many territories at both study sites, some of which were difficult to observe because they were located among tall trees. We observed at least 8 territories in Shiojiri City and 3 in Nagano City. Fig. 3 shows an example of a territory. Males were never observed to feed during their territorial activity.

\section{Circling flight}

We observed 56 circling flights between residents and intruders. The intruder was expelled in all except one case (i.e. residents won $98 \%$ of fights). In the latter case, the resident regained his territory the next day. Of these contests, 11 made by six different residents were recorded with a high-speed video camera and in all of them the loser were found to be males that first ceased the circling flight.

From the detailed observation made on a fixed territory in Nagano City, the initiation points of circling flights were located within or around the inspection area. This is the same for the termination points with three exceptions where males strayed far away from the territory (Fig. 3). We also encountered, at least five times, cases in which two males in circling flight strayed far away from the territory in Shiojiri City. The resident returned to his own territory after the fights.

\section{Mating behavior}

Females were rarely seen and we observed only two

(b)

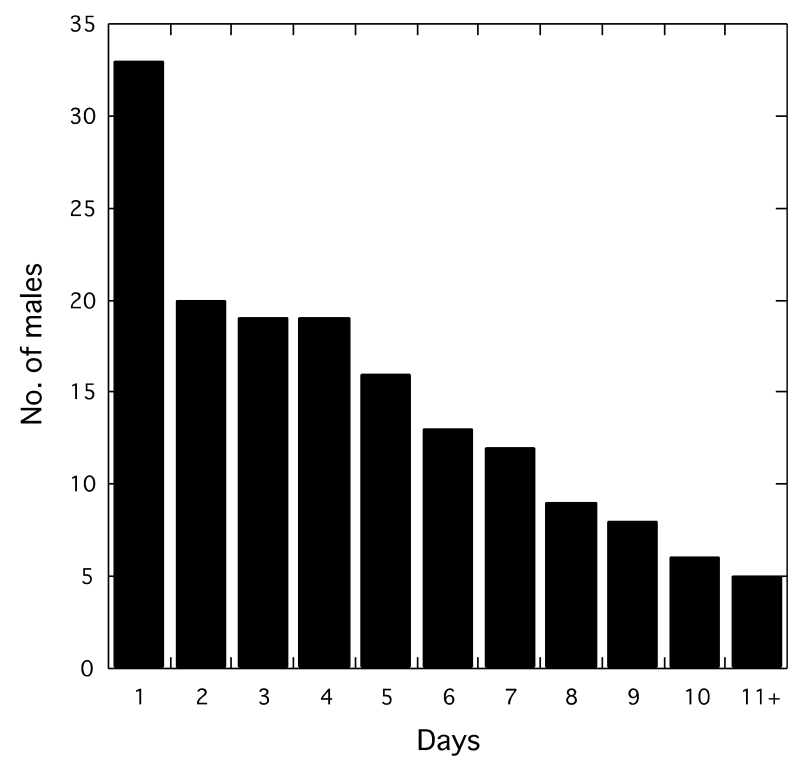

Fig. 2. (a) Frequency distribution of the territory tenure time of male Chrsozephyrus smaragdinus. The five males in the $11+$ days category occupied their territories for periods of $12,13,18,18$ and 28 days. (b) The number of males who remained to occupy the territory on the days shown on the abscissa. 


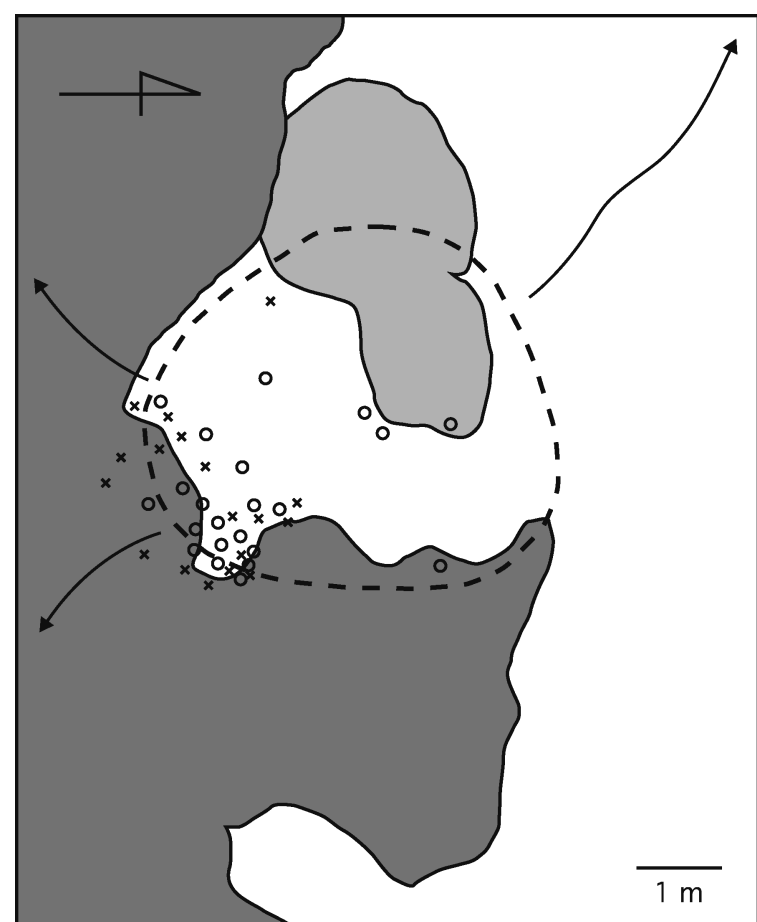

Fig. 3. A map of the territory of a male Chrsozephyrus smaragdinus in Nagano City. Dark gray; tall trees, Light gray; short tree, White; pasture, dashed line; inspection area, circles; location where circling flight was initiated, crosses; location where circling flight was terminated. Arrows indicate that the two males in circling flights strayed far away from the territory.

copulations. One copulation was observed on 28 June 2003 in Nagano City. A female flew into a male's territory at 14:30. The territorial male immediately pursued her. Soon they alighted on a leaf (approximately $7 \mathrm{~m}$ above the ground) of a Diospyros kaki tree near the territory, and copulated. The copulation lasted for 3 hours and 5 min ending at 17:35. After copulation, the male flew away, and the female did so thereafter. Since then until 3 July 2003, the last day of our observation there, this male never returned to the territory that he had defended for the previous 7 days.

Another copulation was observed on 16 June 2004 in Nagano City. We found a mating pair at 14:25 on a leaf (approximately $6 \mathrm{~m}$ above the ground) of a Celtis sinensis tree. The male had defended a territory near the tree from the previous day. After copulation, the male did not continue to hold the territory, although he was found engaging in circling flights.

Courtship behavior was observed on 25 June 2002 in Nagano City. A female flew to a male's territory at 13:30. The territorial male immediately pursued her. Soon they alighted on a leaf (approximately $3 \mathrm{~m}$ above the ground) of a Juglans mandshurica tree near the territory. The male approached her from the left side while fluttering and bending his abdomen tip to her abdomen tip. However, this copulatory attempt ended in failure. The female flew away and the male returned to his territory. After a while, he frequently flew out of his territory to fly around the leaf where he lost the female.

We observed no copulation in Shiojiri City during the 3year observation period.

\section{DISCUSSION}

Male territorial activity time ranged from late morning to late afternoon. This is consistent with previous observations (Koda, 1982). The present study revealed also the difference in the territorial activity time between two locations; it started and ended earlier in Nagano City than in Shiojiri City. This can be partly attributed to the different climate in the different locations. In Shiojiri City, adults appeared in a sunnier and hotter season than those in Nagano City. It would provide them with a more intense light and a higher ambient temperature, which should enable them to be active until later in the day. However, climate cannot explain the later starting time of daily activity in Shiojiri City. The time difference in the territorial activity between Nagano City and Shiojiri City may be attributed to the difference in population size, with smaller number of males in Shiojiri City than that in Nagano City (Fig. 1a,b). Another possible reason may be the existence of a closely related and similar colored species Chrysozephyrus brillantinus. Males of this species were active in the early morning (ca. 8:00 to 10:00; Koda, 1982) and showed territorial behavior at the space where male $C$. smaragdinus also showed territorial behavior in Shiojiri City, while C. brillantinus was absent in Nagano City. Therefore, temporal segregation of territorial space use may be achieved between these species in Shiojiri City. Observation at more sites is necessary to test this hypothesis.

In the present study, the initiation and termination points of circling flight were located in the territory, with the termination points far outside the territory in a few cases. Similar observations are reported in other butterfly species (e.g. Knapton, 1985; Fischer and Fiedler, 2001; Takeuchi and Imafuku, 2005). This seems to be different from what has been observed in other animals: in mammals or birds, aggressiveness frequently declines near the boundary of the territory (e.g. Matsubara, 2003). In butterflies, it appears usual that territories are located at specific terrain features (e.g. Cordero and Soberón, 1990). So, they are not adjacent to each other, but maintain neutral spaces among them. In such spaces, they would continue circling flights.

The resident won the fight with the intruder in $98 \%$ of the cases, and defended his territory for several successive days. The resident's high winning rate has been observed in various animals. This phenomenon is referred to as "effect of prior residence" (Ito et al., 1992), and some hypotheses are presented to explain it. The "bourgeois strategy" hypothesis (Maynard Smith, 1982) suggests that the resident wins because competitors adopt the rule that the resident should be aggressive and the intruder should retreat. Davies (1978) gave empirical evidence supporting the bourgeois strategy in the speckled wood butterfly, Pararge aegeria. However, studies conducted later revealed 
that the bourgeois strategy is rare or non-existent in the wild, both theoretically (Grafen, 1987) and empirically (e.g. Kemp and Wiklund, 2004). Stutt and Willmer (1998) recently presented an alternative hypothesis that residents can achieve a higher body temperature basking in the territory, which enhances their physiological condition, and are therefore more likely to win a contest. In the present study, the thermal condition is not a likely explanation. If the thermal condition is important in contest settlements, residents could not chase away intruders for average 9 days and could not win two to three contests one after another because the thermal condition would often change (e.g. via convective cooling in flight). From the viewpoint of theoretical models, the resident would have higher resource-holding potential (RHP: Parker, 1974) or evaluate the territory more highly than the intruder (Enquist and Leimar, 1987). RHP is routinely correlated with body size in many animals (Andersson, 1994). However, the relation between RHP and body size is not clear in butterflies (e.g. Hernández and Benson, 1998; Kemp, 2000). In the present study, we observed the natural behavior of the butterflies, and therefore, could not collect samples to measure RHP candidates. On the other hand, the resident came to his territory every day, suggesting that they had a clear spatial memory and that the resident should have more knowledge of the territory than the intruder. This suggests the presence of a resource (territory) value asymmetry between the resident and the intruder, and territorial contests may be settled on the basis of the resource-value asymmetry. This hypothesis remains to be tested.

In the circling flight, the loser ceased the flight first and was chased by the winner. This satisfies the premise of "wars of attrition", and gives some validity to consider circling flights as wars of attrition. Moreover, this indicates that only the duration of the circling flight is relevant to working out the aggressive intent of the loser (true contest phase), and the horizontal chase after circling flight is not a true contest phase in which the outcome has already been decided.

We observed two copulations, and both the copulated males, who had been defending territories until mating, did not defend the territory after mating. One of them had been defending his territory for 7 days, and the other for 2 days. Fig. $2 b$ shows that 9 of the 12 males who had been defending their territory till the 7th day continued defending it the next day, and that 19 of the 20 males who had been defending their territory till the 2nd day continued defending it the next day. This implies that copulation imposed some costs to the males, and that they could not defend their territories through fights after copulation. It is known that butterfly males give females ejaculates up to $15.5 \%$ of their body weight (Svärd and Wiklund, 1989). In the sagebrush cricket, Cyphoderris strepitans, the male's physiological condition is worsened by giving the nuptial gift to the female during mating, which diminishes the male's ability to secure another mating (Sakaluk et al., 2004). The effect of mating experience on the following mating in butterflies has been well studied in the laboratory. In general, male ejaculates become smaller in the second mating compared to the first mating (e.g. Watanabe et al., 1998), and it takes several days after copulation to return ejaculate weight to the original level (e.g. Hughes et al., 2000). However, it is not well understood how mating history affects male mating behavior and mating success in nature.

Supposing that territory holding is an effective strategy for males to acquire receptive females, mating experience may restrict the next mating opportunity of the male in $C$. smaragdinus. By contrast, Suzuki and Matsumoto (1992) showed that the first mating experience enhanced the probability of the next mating of the male in the papilionid butterfly, Atrophaneura alcinous. This difference may be attributed to the difference in the male mate-locating strategy between the two species. Males of $A$. alcinous patrol near female emerging sites, do not defend a territoriy and do not compete with conspecific males (Suzuki and Matsumoto, 1992). On the other hand, males of $C$. smaragdinus do not search for emerging females (there were no larval food plants in their territories) but must engage in circling flights to keep their territories for some hours every day. The male after mating may not be physically fit to defend a territory, and mating experience may affect behavioral performance of males. This issue needs to be studied further.

\section{ACKNOWLEDGMENTS}

We are grateful to Masashi Tashita and Mochimitsu Kobayashi for providing valuable information on the study sites, and to $\mathrm{Dr}$ Simon Cook for reviewing drafts. This work was supported in part by a Grant for the Biodiversity Research of the 21 st Century COE (A14).

\section{REFERENCES}

Alcock J, Bailey WJ (1997) Success in territorial defence by male tarantula hawk wasps Hemipepsis ustulata: the role of residency. Ecol Entomol 22: 377-383

Andersson M (1994) Sexual selection. Princeton University Press, Princeton

Cordero CR, Soberón J (1990) Non-resource based territoriality in males of the butterfly Xamia xami (Lepidoptera: Lycaenidae). J Insect Behav 3: 719-732

Davies NB (1978) Territorial defence in the speckled wood butterfly (Pararge aegeria): the resident always wins. Anim Behav 26: 138-147

Enquist M, Leimar O (1987) Evolution of fighting behavior: The effect of variation in resource value. J Theor Biol 127: 187-205

Fischer K, Fiedler K (2001) Resource-based territoriality in the butterfly Lycaena hippothoe and environmentally induced behavioural shifts. Anim Behav 61: 723-732

Fukuda H, Hama E, Kuzuya T, Takahashi A, Takahashi M, Tanaka B, Tanaka H, Wakabayashi M, Watanabe Y (1984) The life history of butterflies in Japan 3. Hoikusha, Osaka (in Japanese with English abstract)

Grafen A (1987) The logic of divisively asymmetric contests: respect for ownership and the desperado effect. Anim Behav 35:462467

Hasegawa M, Tanemura M (1986) Ecology of territory. Tokai University Press, Tokyo (in Japanese) 
Hernández MIM, Benson WW (1998) Small-male advantage in the territorial tropical butterfly Heliconius sara (Nymphalidae): a paradoxical strategy? Anim Behav 56: 533-540

Hughes L, Chang BS, Wagner D, Pierce NE (2000) Effects of mating history on ejaculate size, fecundity, longevity, and copulation duration in the ant-tended lycaenid butterfly, Jalmenus evagoras. Behav Ecol Sociobiol 47: 119-128

Imafuku M, Hirose Y, Takeuchi T (2002) Wing colors of Chrysozephyrus butterflies (Lepidoptera; Lycaenidae): ultraviolet reflection by males. Zool Sci 19: 175-183

Ito Y, Yamamura N, Shimada M (1992) Animal ecology. Sojushobo, Tokyo (in Japanese)

Kemp DJ (2000) Contest behavior in territorial male butterflies: does size matter? Behav Ecol 11: 591-596

Kemp DJ, Wiklund C (2001) Fighting without weaponry: a review of male-male contest competition in butterflies. Behav Ecol Sociobiol 49: 429-442

Kemp DJ, Wiklund C (2004) Residency effects in animal contests. Proc R Soc Lond B 271: 1707-1711

Knapton RW (1985) Lek structure and territoriality in the chryxus arctic butterfly, Oeneis chryxus (Satyridae). Behav Ecol Sociobiol 17: 389-395

Koda (1982) Observation on the male activity of five Japanese species of zephyrus hairstreaks, with special reference to the influence of the light intensity. Tyô to Ga 33: 29-39 (in Japanese with English abstract)

Lederhouse RC (1982) Territorial defense and lek behavior of the black swallowtail butterfly, Papilio polyxenes. Behav Ecol Sociobiol 10: 109-118

Matsubara H (2003) Comparative study of territoriality and habitat use in syntopic Jungle Crow (Corvus macrorhynchos) and Carrion Crow (C. corone). Ornithol Sci 2: 103-111
Maynard Smith J (1982) Evolution and the theory of games. Cambridge University Press, Cambridge

Noble GK (1939) The role of dominance in the social life of birds. Auk 56: 263-273

Parker GA (1974) Assessment strategy and the evolution of fighting behavior. J Theor Biol 47: 223-243

Sakaluk SK, Campbell MTH, Clark AP, Johnson JC, Keorpes PA (2004) Hemolymph loss during nuptial feeding constrains male mating success in sagebrush crickets. Behav Ecol 15: 845-849

Stutt AD, Willmer P (1998) Territorial defense in speckled wood butterfly: do the hottest males always win? Anim Behav 55:13411347

Suzuki N, Matsumoto K (1992) Lifetime mating success of males in a natural population of the papilionid butterfly, Atrophaneura alcinous (Lepidoptera: Papilionidae). Res Popul Ecol (Kyoto) 34: 397-407

Svärd L, Wiklund C (1989) Mass and production rate of ejaculates in relation to monandry/polyandry in butterflies. Behav Ecol Sociobiol 24: 395-402

Takeuchi T, Imafuku M (2005) Territorial behavior of Favonius taxila (Lycaenidae): territory size and persistency. J Res Lepid 38: 59-66

Watanabe M, Wiklund C, Bon'no M (1998) The effect of repeated matings on sperm numbers in successive ejaculates of the cabbage white butterfly Pieris rapae (Lepidoptera: Pieridae). J Insect Behav 11: 559-570

Waage JK (1988) Confusion over residency and the escalation of damselfly territorial disputes. Anim Behav 36: 586-595

Wilson EO (1975) Sociobiology: the new synthesis. Belknap, Cambridge, Mass

(Received December 10, 2004 / Accepted July 20, 2005) 